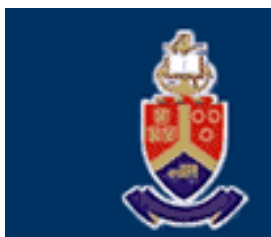

University of Pretoria

University of Pretoria

Department of Economics Working Paper Series

Vicious and Virtuous Circles - The Political Economy of Unemployment

Patrick Minford

Cardiff University

Ruthira Naraidoo

University of Pretoria

Working Paper: 2009-14

June 2009

Department of Economics

University of Pretoria

0002, Pretoria

South Africa

Tel: +27 124202413

Fax: +27 123625207 


\title{
Vicious and virtuous circles - The political economy of unemployment
}

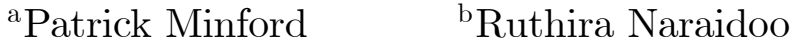

June 2009

\begin{abstract}
We develop an empirical nonlinear model of equilibrium unemployment and test its policy implications for a number of OECD countries. The model here sees the natural rate and the associated equilibrium path of unemployment as endogenous, pushed by the interaction of shocks and the institutional structure of the economy; the channel through which these two forces feed on each other is a political economy process whereby voters with 'limited information' on the natural rate of unemployment react to shocks by demanding more or less social protection. The reduced form results from a dozen OECD economies give support to the model prediction of a pattern of unemployment behaviour in which unemployment moves between high and low equilibria in response to shocks and the model specification is superior in forecasting performance out of sample to alternative models of 'generalised hysteresis'.

Keywords: Equilibrium unemployment, political economy, vicious and virtuous circles, bootstrapping, forecasting

JEL Classification: E24, E27, P16

${ }^{a}$ Cardiff Business School, Aberconway Building, Cardiff University, Colum Drive, Cardiff, Wales, United Kingdom, CF 10 3EU.

${ }^{\mathrm{b}}$ University of Pretoria, Department of Economics, Pretoria, 0002, South Africa. Phone: +27 124203729 , Fax: +27 12362 5207. E-mail: ruthira.naraidoo@up.ac.za. Also author for correspondence.
\end{abstract}




\section{Introduction}

Why is unemployment high in some countries and low in others? Why has the same country experienced high unemployment in some periods of its history and low unemployment in other periods? The economic experience of major OECD economies is one of prolonged bouts of low unemployment and high unemployment. An obvious example is post war continental Europe which grew rapidly with full employment in the 1960s and 1970s but in the 1980s onward there was stagnation and relatively high unemployment with unemployment close to double-digit in some economies up to this date. One can also think retrospectively of the low unemployment associated with the roaring 1920s in the US followed by the mass unemployment of the Great Depression.

How can this be, given we all have access to the same ideas about managing the economy, the same technology, the same world capital markets, to the same sort of skills in our labour forces? In this paper we suggest that, via the processes of political economy, the structure of the economy (especially of the 'supply side') alters in response to shocks, often in an unhelpful way that reinforces these shocks, but also occasionally in a helpful 'revolution' that allows the economy finally to adapt. For example, if there is a persistent slump, voters may demand regulation, strong unions, protection and better unemployment benefits (examples are St. Paul $(1996,2000)$ on the difficulties of modifying costly firing regulations in Europe). The reforms undertaken by the UK and a number of countries in continental Europe in the 1980s exemplify how the economic structure can be improved once perhaps matters have become sufficiently bad for popular support to be built around reform.

The main hypothesis advanced here is that shocks (mainly demand in nature) causing sharp cyclical swings in unemployment and other persistent influences on unemployment (such as demographic and sectorial shifts) generate political reactions from public opinion and vested interests, while these in turn produce not merely fiscal and monetary (demand policy) responses but also changes in supply-side policy, i.e., policy affecting the equilibrium values of real variables or 'natural rates'. Specifically, these shocks tend to produce supply policy that distorts the market because these shocks generate demands for protection; these distortions in turn produce a worse equilibrium with a higher natural rate of unemployment which in turn can reinforce the demands for yet more protection, until matters are bad enough for a political coalition to form around reform. Vice versa, a good run of demand shocks produces more liberal supply-side policies as people are less nervous about potential misfortune. This again is self-reinforcing so that the economy moves in a virtuous circle to a low-unemployment equilibrium. The dynamics of unemployment exhibit three equilibria in almost all cases- one stable low unemployment equilibrium, one stable high unemployment equilibrium and a nonstable intermediate unemployment equilibrium that lies between the two. We thus posit that there are intimate linkages through political economy between the two sorts of policies, namely, demand-management and supply side policies, and these links have the capacity to create both vicious and virtuous circles of economic performance.

The model has two components to it: a standard model of the natural rate of unemployment and a model 
of the political economy of institutions (supply side policies). The political economy model of institutions in this paper extends the analysis of Meltzer and Richard (1981), Wright (1986) and St-Paul (1996). Longlasting shocks to the economy lead to demand for social protection in the labour market. Much as in Meltzer and Richard (1981) the median voter's support for redistributive taxation varies with the state of the economy. In Wright (1986), the more exposed to unemployment is the median voter, the higher the political support for unemployment benefits. In his model, the optimal demand for unemployment benefits is determined by weighing their benefits (in terms of better insurance) against their costs (in terms of higher taxes). However as noted by Saint-Paul (1996), in so far as higher unemployment benefits raise wages and destroy jobs, the higher exposure of the median voter to unemployment will increase the demand for protection in terms of higher unemployment benefits but at a diminishing rate. Thus we address the missing channel of Wright (1986) of how labour market institutions can affect the welfare of the decisive voter, as suggested by St-Paul (1996).

The paper therefore contributes to a large literature on the relationship between economic performance and institutions. North (1981), Lal (1998) and Olson (1971, 1982) have charted the way and set out the mechanisms for the creation and evolution of institutions and the consequence for the general good of the economy. For a recent literature on institutions and the link to economic growth, see, for example, Persson and Tabellini, 1994; Alesina and Roderick, 1993; Perotti, 1993; Stokey and Rebelo, 1993, and Krusell et al., 1997. This basic idea has led to a substantial applied research agenda; examples are St. Paul (2002, 2004) on the difficulties in undertaking reforms in European labour markets.

There is in particular a large literature of 'hysteresis' (see Layard et al. (1991) and Roed (1997)) which has noted the tendency for unemployment to react with high persistence to temporary demand and supply shocks. Indeed, Layard et al. (1991) following Burda (1988) find that long-duration unemployment is closely linked to long-duration benefits as originally posited by Minford (1983). Blanchard and Wolfers (2000) have in this vein identified the interaction of such shocks with 'adverse institutions' such as unemployment benefit regimes. Therefore the paper contributes to a set of other studies explaining the rise in unemployment since the 1970s in terms of macroeconomic shocks interacting with institutional patterns (see for instance, Blanchard and Wolfers, 2000; Fitoussi et al., 2000; Bertola et al., 2001; Nickel et al., (2005); Matthews et al. (2008)). Multiple equilibria also have a long history in the macroeconomics of unemployment (for an early example see Diamond, 1982). Our contribution here is to view these interactions as the product of a political economy process.

In section 2, we start by outlining a standard model of structural unemployment. We then combine this result with a model of optimal demand for social protection derived from a model of political economy of supply side policies. In section 3, we derive our reduced form model and presents our results for the twelve OECD countries under investigation. A bootstrapping test procedure is then developed to determine the number and nature of equilibria. We then test the reduced form model against some general models of hysteresis by providing out-of-sample forecasts comparison. Section 4 concludes. 


\section{The Model}

\section{The Labour Market in outline}

Structural models of the labour market can broadly take two main views: competitive and bargaining models. Under the bargaining approach, Mortensen and Pissarides (1994) among others have developed search and matching models and Shapiro and Stiglitz (1990) among others have developed models under the efficiency wage approach.

Our set-up of the labour market is a competitive one such as Siebert (1997). It is assumed that industry is competitive and each firm enjoys constant returns to scale, yielding a horizontal demand curve for labour given by its marginal value product in Figure 1. Accordingly, we treat real wages, $W$, as exogenously determined by productivity. ${ }^{1}$

Labour supply is 'new classical' in spirit, where worker has knowledge of 'going rates' in the sectors in which he has the necessary skills to work. He decides when to enter and when to withdraw from these sectors in a standard optimising manner by weighing these wage rates and other relevant prices, including benefits out of work and taxes etc. in work.

The model therefore implies that the supply of labour will be dependent on the level of real wages, net of tax and expenses, relative to out of work benefits. Because of the wide differences in individual tax/benefit circumstances tight restrictions across the parameters of benefit, tax, and real wage variables are unlikely to hold and we write labour supply, $L^{s}$, relative to the participating working population, $P O P$, as a function of benefits relative to net real wages:

$$
\frac{L^{s}}{P O P}=f\left(B / W\left(1-T_{L}\right)\right)
$$

where $B=$ real unemployment benefit, $T_{L}=$ tax rate (fraction of wage) paid by employee. In a time-series analysis, we may expect the elasticity of labour supply to the benefit/income ratio to be very low for a low aggregate ratio and to rise as the ratio rises, tending towards a maximum as net wage income tends to the level of benefits provision. Such a supply curve is illustrated in Figure 1.

The labour market equations are completed by the unemployment identity (shown in Figure 1) where we define $U$ as the unemployment rate:

$$
U=\frac{P O P-L_{s}}{P O P}
$$

In Figure 1, one can see how the marginal product of labour schedule (assumed here to be horizontal) can interact with this distorted labour supply schedule to generate equilibrium unemployment. Should the benefit rise relative to productivity, unemployment will result: people will voluntarily refuse to take available

\footnotetext{
${ }^{1}$ Worth noting also is that the 'demand wage relation' can be represented by a horizontal line in real wage-employment space as emphasized by Blanchard and Katz (1997). If we focus on the long-run, the real wage of firms is independent of the level of employment and labour demand depends on productivity, factors that affect the wage firms can pay, for example, employment taxes and the mark-up of price over marginal cost which matters for price-setting firms (i.e., the higher the mark-up, the lower the real wage paid by firms).
} 
wage offers because benefits are preferable. They are 'unemployed' in the sense that they are not working but are 'available for work'.

The labour market model can be generalised to include the effects of union power, taxes of all sorts, employer and employee national insurance contributions (which in Europe are largely taxes in nature) and other forms of labour market intervention such as employment protection, minimum wages. ${ }^{2}$

We choose to enter $\ln U$ (the natural logarithm of the unemployment rate) rather than employment into the supply curve because the theory suggests as above that at high unemployment levels, a $1 \%$ change in benefits will have a larger absolute effect on unemployment levels because the slope of the supply curve will be flatter (more wage rigidity). A log formulation has this property. The labour supply curve can also have a family relationship with a 'wage equation' by normalising on the real wage variable and union power could enter in it to stress its role in wage-setting. It should also be noted that the use of the log of unemployment rate in a 'wage curve' (supply curve) has been found to be preferable to the use of the rate of unemployment in the determination of wages throughout many investigations (Blanchflower and Oswald, 1994).

In our analysis we focus purely on benefit/wage replacement ratio, because this will be the choice variable for voters under our political economy model below; such things as taxation and public expenditure, union power, and minimum wages are also potential choice variables. It should also be noted that some empirical works have been carried out as to the multidimensional nature of preferences for redistribution (see Bernasconi, 2006). But for simplicity we leave them out of the explicit model. Thus our operational equation becomes:

$$
\ln U_{t}=u_{0}+\delta \ln \left(B_{t} / W_{t}\right)+u_{1 t}+u_{t}^{c}
$$

where $u_{0}$ is a constant, $u_{t}^{c}$ is cyclical unemployment, and $u_{1 t}$ represents other persistent influences on unemployment. Examples of such influences would be demographic shifts (like a rise in working age population, and sectoral shifts like a decline in manufacturing). $u_{t}^{c}$ and $u_{1 t}$ would therefore be an error process assumed to display high serial correlation. These influences will have no long-run effect on unemployment (or if they do, it is assumed to be captured in the natural rate equation: $\left.\ln U_{t}^{*}=u_{0}+\delta \ln \left(B_{t} / W_{t}\right)\right)$. However their short-run effect is assumed to be long drawn out.

\section{The Political Economy of the Supply Side}

In a series of contributions, Saint-Paul (2000, 2002, 2004) has looked at the pressures from interest groups such as the employed and unemployed to explain the existence of labour market institutions such as employment protection, unemployment benefits, and relative wage rigidities. In our model, the median

\footnotetext{
${ }^{2}$ In the UK, Layard and Nickell (1986) estimated a similar model within a non-competitive framework, and Bean et al. (1986) attempted to extend it to other European countries which began to experience rising unemployment UK-style during the late $1980 \mathrm{~s}$ and $1990 \mathrm{~s}$. It turns out that in each country there are substantial idiosyncracies in the social support mechanisms, complicating effective modelling of the natural unemployment rate. Nevertheless a large amount of empirical work, both crosssection (Burda(1988) was the first to exploit the variation across European countries and show the importance of long-duration benefits) and time-series Nickell (1998) and Layard, Nickell and Jackman (1991) survey much of it, seemed to confirm that these mechanisms, particularly the length of time benefits were available and their ease of eligibility, were responsible for persistently high unemployment in Europe.
} 
voter holds some non-human capital but nevertheless relies heavily on income from human capital. If this voter experiences unemployment spells, unemployment benefits yield a much needed replacement of wage income. The higher level of unemployment means that agents are more exposed to the risk of being unemployed which therefore increases their desired benefit/wage replacement ratio. However, we also take into account the feedback distortionary effect of benefit on unemployment which increases the probability of unemployment for the median voter. Hence as unemployment rises, the median voter's demands for benefits rise but at a diminishing rate, as these higher benefits progressively raise the chances of unemployment.

We expound this model in the first place under the assumption of rational expectations with full information up to time t- 1 on the relevant data and full knowledge of all model parameters. We then look at the case of limited information on the part of voters about the natural rate of unemployment.

\section{Under Rational Expectations:}

Let the median voter's utility be given purely by a linear function of income so that the mth such voter maximises at $\mathrm{t}^{3}$ :

$$
V_{t}^{m}=E_{t} \sum_{i=0}^{\infty} \beta^{i}\left(N_{t+i}^{m} s B_{t+i}+\left[1-N_{t+i}^{m} s\right] W_{t+i}+r K-T\right)
$$

where $\beta=$ the voter's time-preference rate, $N_{t+i}^{m}$ is the number of spells the mth voter spends unemployed in year $\mathrm{t}+\mathrm{i}, s=$ fraction of a year that each spell lasts; $r$ is the rate of return on non-human capital, $K$, and $T=$ general per capita taxation (treated as lump sum). In addition this voter faces two constraints. First, the expected duration of unemployment in $\mathrm{t}+\mathrm{i}$ (that is $s$ times the expected number of spells) is $\pi_{t+i}$ which we write as:

$$
\pi_{t+i}=\pi_{0}+\pi U_{t+i} \quad ; \quad 0 \leq \pi_{t+i} \leq 1
$$

Note that $U$ (the rate of unemployment) $=s(N / P O P)$ where $N / P O P$ is the average number of spells per head of working population, that is the 'turnover rate' (fraction of jobs lost per annum). Therefore if the median voter is typical; $\pi_{t+i}=U_{t+i}$ so that $U=\frac{\pi_{0}}{1-\pi}$. We expect $\pi_{0}$ to be small and positive, on the grounds that the chances of becoming unemployed never go to zero however low unemployment may go; and $\pi$ to be positive and less than unity, if we assume (as we do) that the median voter's chances of unemployment are approximately the same as the population's.

The second constraint comes from the economic model of unemployment (namely, equation (3)) and is written as equation (6):

$$
U_{t+i}=\exp \left(u_{0}+v_{t+i}\right) \cdot\left[B_{t+i} / W_{t+i}\right]^{\delta}
$$

where $v_{t+i}=u_{1 t+i}+u_{t+i}^{c}$.

The first order condition from maximising equation (4) yields the solution for the median voter's desired

\footnotetext{
${ }^{3}$ St. Paul (1996) has a simplified static welfare function of this type for the decisive voter. He points out how the individual's welfare is affected by a labour market institution through the following four main channels; the probability of remaining employed, the income while remaining employed, the income while unemployed and the tax paid by the employed.
} 
benefits as:

$$
\left(\ln B_{t}-\ln W_{t}\right)=\frac{\eta}{1-\delta \eta} \bar{v}_{t}^{e}+\text { constant }
$$

Appendix (1) provides a full derivation of equation (7). The interpretation of equation (7) is that voters are altering their benefit demands (which in turn control changes in the natural rate) in response to that part of unemployment, $\bar{v}_{t}^{e}$, the permanent value of persistent cyclical and other movements in unemployment, that they cannot control.

We have assumed rational expectations conditional on voters' information set. However, it is clear that within this model if voters know the correct value of $v_{t}$ and of the natural rate, $U_{t}^{*}$, then their demands for benefits would be self-limiting, as exemplified by equation (7). What would occur would be that faced with a persistent $v$ shock to unemployment they would demand higher benefits which would raise unemployment temporarily, until the shock had disappeared. This would produce an extended cycle in the natural rate and in the benefit-wage ratio around a single steady state equilibrium; but it would not produce the very large and apparently self-propagating movements in the natural rate of unemployment that we observe quite widely. However, it is worth bearing such a model of full information in mind as it is possible that in some countries' episodes information is sufficiently full to avoid this phenomenon and hence produce a single unemployment equilibrium.

\section{Under Limited Information:}

At this point we introduce an important information limitation. Instead we assume that the voters' general situation is one of limited information about the natural rate and hence about the other $v$ shocks disturbing unemployment. ${ }^{4}$ By implication they also have limited information about the parameters. Indeed as recently as the 1970s it was commonplace among economists influential in policy to deny the existence of a natural rate. Hence we would argue that for our post-war episodes it is quite reasonable to assume that voters faced a signal extraction problem. They observed $U_{t-1}$ but could not decompose it into $v_{t-1}$ and the natural rate. To solve this in a standard way, we assume that they used past experience (prior to the sample) on the ratio, $\xi$, of the variance of $v_{t}$ to the total variance of the unemployment rate. In the model here they apply this ratio to the rise in unemployment since some initial rate, $z$.

Thus their estimate of $v_{t}$ is $E_{t-1} v_{t}=\xi\left(U_{t-1}-z\right)$ and of the natural rate is $E_{t-1} U_{t}^{*}=(1-\xi)\left(U_{t-1}-z\right)$. Hence the permanent value of $\bar{v}_{t}^{e}=\theta E_{t-1} v_{t}$ where $\theta$ is determined by the coefficients of the $v$ autocorrelation function and the discount rate. $E_{t-1} U_{t}^{*}$ is treated as a constant, as it depends on $B_{t} / W_{t}$ which is expected to be constant by virtue of the voter's optimising choice. We recall that $\frac{\eta}{1-\delta \eta}$ is a declining function of the permanent value of lagged unemployment $\bar{U}_{t-1}$ (derived in Appendix 1); under our limited information assumption this parameter becomes an estimated one, $\frac{\widehat{\eta}}{1-\delta \eta}$, to be updated on the basis of the latest estimates of the $v$ shock and the natural rate, in conjunction with other information about the model. The best estimate

\footnotetext{
${ }^{4}$ This limitation is motivated by the sheer difficulty and indeed controversy that has surrounded the estimation of natural rates for different economies.
} 
of $\bar{U}_{t-1}$ is $E_{t-1} \bar{U}_{t-1}=\bar{v}_{t}^{e}+E_{t-1} U_{t}^{*}=[1-\xi(1-\theta)]\left(U_{t-1}-z\right)$. We represent the function here linearly as:

$$
\frac{\widehat{\eta}}{1-\delta \eta}=\psi_{1}-\psi_{2}\left(U_{t-1}-z\right)
$$

We can now write:

$$
\left(\ln B_{t}-\ln \bar{W}_{t}\right)=\left[\psi_{1}-\psi_{2}\left(U_{t-1}-z\right)\right]\left[\theta \xi\left(U_{t-1}-z\right)\right]+B_{0}+\epsilon_{t}
$$

where we have added an error term, $\epsilon_{t}$, to capture the influence of other factors and pieces of information on the choice of optimal benefits. Hence finally we obtain a reduced form equation for benefit-wage ratio as:

$$
\ln \left(B_{t} / \overline{W_{t}}\right)=B_{0}+\varphi\left(U_{t-1}-z\right)-\beta\left(U_{t-1}-z\right)^{2}+\epsilon_{t}
$$

where $\varphi=\psi_{1} \theta \xi$ and $\beta=\psi_{2} \theta \xi$.

Therefore equation (10) represents the second component of the model which is the political economy demand for unemployment benefits modelled as the replacement rate being determined by a lag in the rate of unemployment given that initially a rise in unemployment above some normal rate, $z$, would trigger demands for higher benefits. The quadratic term captures the feature that as unemployment increases the demand for unemployment benefits increases but at a decreasing rate. In equation (10), $B_{0}$ is a minimum benefit/wage ratio set in normal circumstances and $\varphi$ and $\beta$ are constants.

Combining equations (3) and (10) leads to the following log-linear reduced form dynamic unemployment model:

$$
\ln U_{t}=\left(u_{0}+\delta B_{0}-\delta \varphi z-\delta \beta z^{2}\right)+(\delta \varphi+2 \delta \beta z) U_{t-1}-\delta \beta U_{t-1}^{2}+u_{1 t}+u_{t}^{c}+\delta \epsilon_{t}
$$

Equation (11) can be written more compactly as:

$$
\ln U_{t}=a_{0}+a_{1} U_{t-1}+a_{2} U_{t-1}^{2}+\xi_{t}
$$

where $a_{0}=u_{0}+\delta B_{0}-\delta \varphi z-\delta \beta z^{2}, a_{1}=\delta \varphi+2 \delta \beta z, a_{2}=-\delta \beta$, and $\xi_{t}=u_{1 t}+u_{t}^{c}+\delta \epsilon_{t}$ is the error process. Then parameters $a_{0}, a_{1}$ and $a_{2}$ determine the dynamics of $U_{t}$ - the mean reversion speed of the deterministic component of unemployment. 


\section{Empirical results}

\subsection{Reduced form solutions and results}

We begin our empirical work by estimating equation (12) for the broad set of countries in the post-war period. ${ }^{5}$ Table 1 summarises the minimum and maximum values of each series, together with their mean, median, standard deviation, skewness and kurtosis. There is a marked difference between the maximum and the minimum values of the series. A common observation of the mean and the median values tells us that the means are upward biased and the series are highly skewed to the right in most cases. Table 2 reports the ordinary least squares estimates for the model, together with their Newey-West standard errors in parenthesis which correct for heteroscedasticity and autocorrelation. The diagnostic tests show no serious misspecification in Table 2. Also, we include any of the first four significant lags of the error process $\xi_{t}{ }^{6}$ in the regression (higher lags prove to be irrelevant) on account of the theory which predicts that $u_{t}^{c}$ (cyclical influences) and $u_{1 t}$ (other structural influences), and hence $\xi_{t}$ will be persistent. The coefficients on the lag error terms turn out to be significant, with the implied roots in these processes all less than unity. The parameters of interest, i.e., $a_{0}, a_{1}$ and $a_{2}$ are in almost all cases statistically significant and we can observe that $a_{2}$ has the correct negative sign in all models, implying mean reversion.

Taking the natural exponential function of equation (12), we end up with equation (13) and setting $e^{\xi_{t}}$ $=1$, i.e., turning off the supply and demand shocks as represented by $\xi_{t}$, we focus on the deterministic path of unemployment and obtain the following non-linear relationship:

$$
U_{t}=\exp \left(a_{0}+a_{1} U_{t-1}+a_{2} U_{t-1}^{2}\right)
$$

We solve $U_{t}-\exp \left(a_{0}+a_{1} U_{t-1}+a_{2} U_{t-1}^{2}\right)=0$ and show the numerical values of the unemployment equilibria (low, middle and high) in Table 3 . We also plot $U_{t}$ against $U_{t-1}$ of the corresponding estimated functions in equation (13) based on the estimated parameters together with a $45^{0}$ line to display the equilibrium points in Figure 3.

An equilibrium lies on the $45^{0}$ line: the actual unemployment rate $\left(U_{t}\right)$ on the y-axis equals the last period unemployment rate $\left(U_{t-1}\right)$ on the x-axis. Although the curve $U_{t}=\exp \left(a_{0}+a_{1} U_{t-1}+a_{2} U_{t-1}^{2}\right)$ could be below, above or move closely with the $45^{0}$ line depending on the relative magnitude of $a_{0}, a_{1}$, and $a_{2}$, if $a_{2}<0$, then for the interval $(U,+\infty)$ we have $U_{t}=\exp \left(a_{0}+a_{1} U_{t-1}+a_{2} U_{t-1}^{2}\right)>0$.

We can interpret the dynamics and equilibria of unemployment by inspecting the phase diagrams in Figure 3. For sake of space we have shown the cases of Spain and the US given that all other countries

\footnotetext{
${ }^{5}$ The set of countries: Denmark (1970.1-2008.1, 153 obs), Finland (1960.1-2008.1, 194 obs), France (1967.4-2008.1,163 obs), Germany (1962.1-2008.1, 186 obs), Ireland (1960.1-2008.1, $194 \mathrm{obs})$, Italy (1960.1-2008.1, 193 obs), the Netherlands (1975.12008.1, 134 obs), Norway (1972.1-2008.1, 146 obs), Spain (1964.2-2008.1, 177 obs), Sweden (1970.1-2008.1, 154 obs), UK (1960.1-2008.1, 194) and the US (1960.1-2008.1, $194 \mathrm{obs})$. All the series are sourced from OECD database.

${ }^{6}$ We also make an explicit estimate of $u_{t}^{c}$ as $a_{3} u_{t}^{c}$, where $u_{t}^{c}$ is the deviation of the log unemployment rate from its HodrickPrescott filter value and the results turn out to be quantitatively similar.
} 
display three equilibria similar to Spain with the exception of the US. Spain represents a clear example of three equilibria, other countries with three equilibria such as Italy, Ireland and Norway have their curves rather close to the 45 degree line. We develop a statistical test further down to distinguish between one and three equilibria countries.

There are basically two groups of countries here:

A. those which move between a low and a high equilibrium unemployment rate as suggested generally by our theory (Denmark, Finland, Sweden, France, Germany, Ireland, Italy, the Netherlands, Norway, Spain and the UK).

B. those which have one low equilibrium rate; the US being the only case.

In Figure 3 and Table 3, the low unemployment equilibrium is a stable position and conforms with the European experience of the early 1960s and 1970s periods. Once the economy experiences large cyclical shocks, unemployment follows more persistent dynamics but mean reverts globally, implying a high unemployment equilibrium rate. The political process discussed earlier comes into play following large shocks to the economy. The estimates suggest a plausibly high top equilibrium rate of unemployment in eleven countries during the 3 -equilibrium period. The estimates for the European economies are consistent with Nickell (1997) and van der Horst (2003) findings based on a structural model where the equilibrium unemployment rates in the European economies were found to depend on policy variables like the wedge, the replacement rate and the statutory minimum wage and, in addition on capital costs.

A-countries behave very much in the mainstream suggested by our theory, moving between a low and high unemployment equilibrium (the middle being unstable). It is striking that all of them have a 'mixed' ideological history, having adopted both relatively 'capitalist' and 'socialist' policies during their post-war history. Thus for example the UK, starting from low unemployment, pursued socially interventionist policies for virtually all the post-war period, then carried out a determined reform programme in 1979. Similar swings have occurred in the Netherlands, Spain, Denmark, Sweden and Ireland. In the case of Norway, the dominant ideology favours active labour market intervention to maintain full employment: thus high benefits for the unemployed are matched by active pressure back to work. This expensive programme has been facilitated by Norway's relatively large oil and gas revenues from the North Sea. Countries which have not (yet at least) pursued the last leg of reform are France, Germany, Italy and Finland. ${ }^{7}$

B-countries are the exceptions where voters' social demands appear to be fairly insensitive to shocks. It would appear that (perhaps after its interwar experiment with the New Deal) US voter opinion is hostile to labour market intervention in line with its general espousal of free markets. What our theory suggests is that such a country's unemployment is dominated by purely cyclical movement and that this in turn induces voters to assume that there is no movement in the natural rate of unemployment to be protected against.

\footnotetext{
${ }^{7}$ See Elmeskov et al. (1998), and Fitoussi et al., (2000) among others for identifying several countries as having accepted the OECD Secretariat proposals for labour market reform.
} 
Plainly such cycle-dominance can only occur in labour markets which are either highly flexible or where active government policy substitutes for this flexibility (in the latter case, the expensive programme can only be facilitated by countries having huge reserves).

Thus there seems to be a general picture of unemployment responding to political pressures, with only one exception in which, mechanisms exist to make unemployment mean-revert quickly to its equilibriummechanisms that avoid the 'circles' we are focusing on.

\section{$3.2 \quad$ Multiple equilibria $\mathrm{v} / \mathrm{s}$ single equilibrium}

The approach taken here is to use the Newey-West correction for the basic results but to augment these by deriving standard errors and actual confidence intervals for the distribution of the relevant coefficients by means of bootstrap procedure, originally developed by Efron (1979) and reviewed more recently by Li and Maddala(1996). Equation (12) in the text is reestimated for each of the 1000 artificial samples. The results are little different from those with 300 bootstraps, suggesting that the distributions have well converged by 1000. The full-sample bootstrap results are presented in Table 4.

The summary of the results of the bootstrap are very similar to the OLS results and the point estimates of the standard errors are similar to those obtained from the Newey-West correction.

However, the key issue of this paper is whether a country is or is not subject to vicious/virtuous circles, in the sense of having three equilibria (the middle one being unstable) rather than merely one. Our central results imply that only the US is a 1-equilibrium country and the rest 3-equilibrium. We wish to develop a statistical test on the joint values of the 3 parameters $\left(a_{0}, a_{1}, a_{2}\right)$ determining the number of equilibria. We carry out two sorts of test based on the bootstrapped parameter distributions.

First, we use these distributions to generate the percentage of 3-equilibrium joint-values for our single 1-equilibrium country and the percentage of 1-equilibrium joint-values for our 3-equilibrium countries. We found the following: our 1-equilibrium country, the US, generated 50\% 1-equilibrium, 50\% 3-equilibrium outcomes. Our 3-equilibrium countries (Denmark, Finland, France, Germany, Ireland, Italy, the Netherlands, Norway, Sweden, Spain and the UK) generated only 3-equilibrium outcomes. These bootstrap distributions give us some information about the likelihood that 1-equilibrium countries could be 3 -equilibrium ones and vice versa. For example, the US clearly has virtually no chance of being a 3-equilibrium country with parameters as estimated for all the other countries since their distributions do not include any 1-equilibrium cases. On the other hand, since $50 \%$ of the US parameter distribution are 3-equilibrium cases, we cannot be at all sure that our 3-equilibrium countries are not 1-equilibrium.

We would obviously like to generate more precise confidence statements. To this end we use a second test based on the slope of the $U_{t}$ function at its mean. This can be understood as follows.

Figure 4 illustrates UK and the US phase diagrams for example, together with the calculated slope $\sigma$, which we define as $\partial U_{t} / \partial U_{t-1}=\left(a_{1}+2 * a_{2} * U_{t-1}\right) \exp \left(a_{0}+a_{1} U_{t-1}+a_{2} U_{t-1}^{2}\right)$ of their respective functions in the lower panel. Considering a 3 -equilibrium model, we can see that the slopes at the low and high 
stable equilibriums are necessarily less than one and a prerequisite to having a 3-equilibrium model is the presence of a middle unstable equilibrium with a slope greater than one. Thus a 3-equilibrium model requires: $\partial U_{t} / \partial U_{t-1}>1$ over some central range of values which we represent by the mean, whereas the slope of a 1-equilibrium model never exceeds $1 .^{8}$ If the slope is 1 exactly over some range, then it implies a degree of ambiguity in the equilibrium state since in effect the whole of that range is in equilibrium; such a country is on the borderline of being the 1- and the 3-equilibrium type. This as we see is the case for the US. Therefore for an unambiguous 1-equilibrium case, $\sigma$ would be less than 1 and for unambiguous 3-equilibrium case, $\sigma$ will be greater than 1. $\sigma$ is thus a measure of the extent to which the combination of parameters diverges in either direction from the borderline case.

In Figure 5 we show various countries distributions over $\sigma$, the (estimated) slope at that country's mean unemployment rate. The figure enables us to make pairwise comparisons of countries. Thus, for example, we can say that Germany's $\sigma$ could not belong to a US style distribution nor the US's belong to a German-style one because the highest $\sigma$ value of the US distribution is smaller than the smallest $\sigma$ value of the German distribution.

We can go further and test the hypothesis that $\sigma=1$, the cross-over point between the 1- and 3equilibrium cases. Thus for each country's $\sigma$ we can compute the chances of it being generated by a $\sigma=1$ distribution and define the $95 \%$ and $99 \%$ confidence intervals for $\sigma \succ 1$ and $\sigma \prec 1$. This enables us to classify countries into three groups: 1 - and 3 -equilibrium with $99 \%$ confidence and ambiguous. The US estimated slope of the phase diagram in its middle or average region $(\sigma)$ is unity (the summary statistics is given in Table 5), so its bootstrapped distribution is the critical one, i.e., it is the distribution of estimated parameters that occurs if the true parameter is 1 . Thus it turns out that the chances of getting an estimated parameter of 1.04 or above is $0.5 \%$ when the true value is unity. Table 5 and Figure 5 show these distributions, together with the estimated $\widehat{\sigma}$ for all the other countries. Plainly these $\widehat{\sigma}$ convincingly reject the hypothesis that $\sigma=1$. The other countries have estimated parameters of over 1.04 in all cases (some of them have values massively greater, e.g, Spain). Hence we can be confident that all countries other than the US are 3 -equilibrium cases. For the US however we cannot be at all sure whether it is 1- or 3-equilibrium: indeed, as we have seen, it lies precisely on the borderline of the two, so that we could say it is equally likely to be either.

\subsection{Comparison against rival 'general hysteresis' models}

The reduced form equations we have estimated are derived from the theoretical model set out above. However, other models have been proposed that make unemployment dependent on its past. The term 'hysteresis' suggests that the current equilibrium unemployment rate may depend strongly on the past level of actual unemployment. Steadily increasing European unemployment rates over the past three decades have led to a substantial research agenda on models of hysteresis in unemployment as originally propounded by Blanchard

\footnotetext{
${ }^{8} \sigma=\partial U_{t} / \partial U_{t-1}$ at mean unemployment, $\bar{U}=\left(a_{1}+2 * a_{2} * \bar{U}\right) \exp \left(a_{0}+a_{1} \bar{U}+a_{2} \bar{U}^{2}\right)$
} 
and Summers (1986). Røed (1997) has reviewed the literature on hysteresis whereby a variety of theories have been proposed for the existence of such hysteresis and has concluded that the unit root hypothesis (pure hysteresis) has rarely been rejected in the relevant theory; let us call them models of 'generalised hysteresis'. These models do not in general have the same implications as ours that there may be two stable equilibira; rather they suggest that unemployment has great persistence and may be non-stationary. If non-stationary they would have potentially an infinite number of equilibria or natural rates, each shock creating a new one. ${ }^{9}$

Besides the theoretical underpinnings of our model, we also propose an empirical test of our reduced form against one of generalised hysteresis. We allow the alternative model to be represented by the bestfitting ARMA/ARIMA or non-linear time series process we can find. Within sample we would expect the fit of such alternatives against our particular form to be barely distinguishable, given the high correlations between different transformations of unemployment and its lags. However, the key distinguishing feature of our model from these general time series representations lies in its forecast implications, namely that the equilibrium to which the economy returns depends on the size of the shocks; small shocks do not alter the economy's local equilibrium but at low unemployment large positive shocks drive unemployment to a high unemployment equilibrium, while at high unemployment large shocks, both positive and negative, drive it back to low unemployment. A general time series process will forecast unemployment either to stay roughly where it is if non-stationary; or, if stationary, to revert to some deterministic equilibrium. Thus the rival models' forecast implications are quite different. We use this as the basis for a repeated forecasting test, where we produce non-nested forecast tests for each date in the sample for each model.

In our forecasting experiment, our purpose is to compare the out-of-sample forecasts of three alternative models; the reduced form model, the best fitting ARIMA/ARMA, and the best-fitting non-linear time series process (represented by a polynomial in the log of unemployment on its lags and powers of its lags). ${ }^{10}$ We also provide the in-sample fit statistics of the alternative models in Table 6 . The best ARIMA model turns out to be an ARMA model and the best polynomial model is one where all the powers are insignificant, adding nothing to the ARMA component. Hence the chosen best rival models of hysteresis are ARMA models with an inverted AR root close to one. The choice of the rival model was made on the criteria of the Akaike information criterion and Schwarz criterion to give a guide for the appropriate lag order selection. For instance, an $\operatorname{ARMA}(1,3)$ is the rival representation for the UK and is given by equation (14) and the summary statistics are given in Table 6. Other countries have different ARMA processes and in the case of Italy, an $\mathrm{AR}(1)$ model turns out to be the alternative specification.

$$
\ln U_{t}=\alpha+\beta \ln U_{t-1}+\epsilon_{t}+\theta_{1} \epsilon_{t-1}+\theta_{2} \epsilon_{t-2}+\theta_{3} \epsilon_{t-3}
$$

Our model is denoted by M and the rival ARMA model by R. Table 6 shows that based on the goodness

\footnotetext{
${ }^{9}$ It is worth noting that Bianchi and Zoega (1998) and Skalin and Teräsvirta (2001) assume that the unemployment rate is globally stationary but possibly nonlinear and locally nonstationary.

${ }^{10}$ Note that comparing our model against non-linear but globally stationary exponential smooth transition autoregressive processes is beyong the scope of this study.
} 
of fit measure $\left(\bar{R}^{2}\right)$, the two models are virtually indistinguishable. The ratio $\hat{\sigma}_{M} / \hat{\sigma}_{R}$ where $\hat{\sigma}_{M}, \hat{\sigma}_{R}$ are the residual standard errors of the $\mathrm{M}$ model and the $\mathrm{R}$ model respectively, provides a measure of in-sample fit comparison for the alternative models. We devise a test of distinguishability based on the bootstrapped distribution of $\sigma_{M} / \sigma_{R}$. To this end, we perform 1000 bootstraps of the M model to give 1000 pseudo samples of the dependent variable $y_{t},\left(=\ln u_{t}\right)$ and we perform the same procedure for the $\mathrm{R}$ model. Under the null hypothesis of generalised hysteresis, the predictions of the two models will be the same and the two processes are indistinguishable. In this case the bootstraps from each process can be pooled, i.e., we have 2000 samples out of the two lots of 1000. The question then is, under this assumption that the two models are the same, what would be the distribution of $\sigma_{M} / \sigma_{R}$ ? We obtain this by a regression of both $\mathrm{M}$ and $\mathrm{R}$ on the 2000 bootstraps. Based on their standard errors, we compute the $95 \%$ limits of the $\sigma_{M} / \sigma_{R}$ in Table 6 . The estimated $\hat{\sigma}_{M} / \hat{\sigma}_{R}$ based on the actual samples all lie well within the $95 \%$ interval; therefore we cannot reject the null hypothesis of indistinguishability for the in-sample fit.

We retain $m=40$ observations for out-of-sample forecasting. In particular we will calculate one step ahead forecasts for the period 1998/Q2 onwards. In order to reduce parameter uncertainty, both models were re-estimated for each observation added to the sample after the date 1998/Q1 and the forecasts are based on the "updated" parameter estimates. The forecast valuation will be based on two different criteria. Let $\hat{y}_{T_{0}+j \mid T_{0}+j-1}$ denote the forecast of $y_{t},\left(=\ln u_{t}\right)$, at time $T_{0}+j$ given information up until time $T_{0}+j-1$ where $T_{0}$ corresponds to $1998 / \mathrm{Q} 1$.

The mean squared prediction error (MSPE) is given by

$$
M S P E=\frac{1}{m} \sum_{j=1}^{m}\left(\hat{y}_{T_{0}+j \mid T_{0}+j-1}-y_{T_{0}+j}\right)^{2}
$$

Although this measure can provide a first indication on whether a certain model performs better on average (in terms of minimizing the respective loss function), it cannot provide statistical significance results on the difference of forecasts.

In order to test the null hypothesis of equal forecasting accuracy we will employ the following tests. Consider the sample path $\left\{d_{j}\right\}_{1}^{m}$ of a loss differential series, that is, $d_{j}$ is a function of the difference of forecast errors produced by the two different models $\mathrm{M}$ and R. For our application we chose the quadratic function:

$$
d_{j}=\left(\left(\hat{y}_{T_{0}+j \mid T_{0}+j-1, M}-y_{T_{0}+j}\right)-\left(\hat{y}_{T_{0}+j \mid T_{0}+j-1, R}-y_{T_{0}+j}\right)\right)^{2}
$$

Diebold and Mariano (1995) propose the use of an asymptotic statistic which tests whether the average loss differential is significantly different from zero. ${ }^{11}$ Specifically they show that,

\footnotetext{
${ }^{11}$ It should also be noted that the literature (namely West $(1996,2001)$ and West and McCracken (1998)) has challenged DM-type statistics. The two grounds are that firstly when computation of the point forecast involves models with estimated parameters and secondly the correlation of prediction errors may not be asymptotically irrelevant and they may enter the limiting distribution of the test statistics. However for one-step ahead prediction, we would assume that parameter uncertainty
} 


$$
D M=\frac{\bar{d}}{\sqrt{\hat{\omega} / m}} \rightarrow_{d} N(0,1)
$$

where $\hat{\omega}$ is an estimate of the long run covariance matrix of $d_{j}$.

Our results are summarized in tables 7 and 8. In all cases the nonlinear model produces the smaller MSPEs. The DM test confirms at the $5 \%$ or $10 \%$ significance levels that the forecast accuracy is not equal in 10 out of 12 cases (with 8 cases being significant at the $5 \%$ level). The DM test does not reject the null of equal predictive accuracy only in Denmark and Norway. In sum, the out-of-sample forecasting test discriminates in favour of our specific nonlinear model against one of generalised hysteresis.

\section{Conclusion}

In this paper we have developed a model in which there is feedback via the political process, combined with limited information on the natural rate, from unemployment to the social protection afforded to the unemployed and so back to unemployment. This feedback generates a non-linear response of unemployment to its own past, with a capacity for two stable equilibria, one high and one low. Reduced form estimates of such a non-linear function suggest that in the postwar period all 12 OECD economies examined exhibited two such equilibria, with the possible exception of the US which is borderline between this and exhibiting only one. This theory both fits the data in its own terms and is superior in forecasting performance out of sample to alternative models of 'generalised hysteresis' which within sample are empirically indistinguishable for familiar reasons.

The paper has a number of policy implications. One is that good macroeconomic management has a role in supporting good supply-side policy. Another is that given making a flexible labour market is widely regarded as a key factor in encouraging economic prosperity while at the same time providing a good level of social protection is one of the main challenges of the government for economic and social reform, education of public opinion in the nature of the economy and the shocks hitting it can avoid counter-productive demands for social protection. Yet another is that reform programmes or demand shocks which overall jolt the economy away from the high unemployment equilibrium can be beneficial.

is a minor concern and that correlation of prediction errors is absent. 


\section{References}

[1] Alesina A, Roderick D., 1993. Redistributive politics and economic growth. Harvard University, manuscript.

[2] Bean CR, Layard PRJ, Nickell SJ., 1986. The Rise in Unemployment: A Multi-Country Study. Economica; $53 ; 1-22$.

[3] Bentolila S, Bertola G., 1990. Firing costs and labour demand: how bad is Eurosclerosis?. Review of Economic Studies; 57; 381-402.

[4] Bernasconi, M., 2006. Redistribution taxation in democracies: Evidence on people's satisfaction. European Journal of Political Economy; 22; 809-837.

[5] Bertola G, Blau FD, Kahn L., 2001. Comparative Analysis of Labour Market Outcomes: Lessons for the US from International Long-Run Evidence. CEPR Discussion Papers; 3023.

[6] Bianchi M, Zoega G., 1998. Unemployment persistence: Does the size of the shock matter? Journal of Applied Econometrics;13; 283-304.

[7] Blanchflower DG, Oswald AJ., 1994. The Wage Curve. The MIT Press, Cambridge Mass.

[8] Blanchard OJ, Summers LH., 1986. Hysteresis and the European Unemployment Problem. NBER Macroeconomics Annual, MIT Press, Cambridge Mass.

[9] Blanchard OJ, Katz L., 1997. What We Know and Do Not Know About the Natural Rate of Unemployment. Journal of Economic Perspectives; 11; 51-72.

[10] Blanchard OJ, and Wolfers J., 2000. Shocks and Institutions and the rise of European Unemployment: The Aggregate Evidence. Economic Journal; 110; 1-33.

[11] Burda M., 1988. Wait unemployment in Europe. Economic Policy; 7; 391-416.

[12] Diamond P., 1982. Aggregate Demand Management in Search Equilibrium. Journal of Political Economy; 90; 881-894.

[13] Diebold FX, Mariano S., 1995. Comparing predictive accuracy. Journal of Business and Economics Statistics; $13 ; 253-263$.

[14] Elmeskov J, Martin J, Scarpetta S., 1998. Key Lessons for Labour Market Reforms: Evidence from OECD Countries' Experience. Swedish Economic Policy Review; 5; 205-252.

[15] Efron B., 1979. Bootstrap methods: Another look at the jackknife. The Annuals of Statistics; 7; 1-26.

[16] Fitoussi JPD, Jestaz D, Phelps ES, Zoega G., 2000. Roots of the recent recoveries: Labor Reforms or Private Sector Forces. Brookings Papers on Economic Activity; 1; 237-312. 
[17] Krusell P, Quadrini V, Rios-Rull JV., 1997. Politico-economic equilibrium and economic growth. Journal of Economic Dynamics and Control; 21; 243-272.

[18] Lal D., 1998. Unintended consequences- the impact of factor endowments, culture and politics on longrun economic performance. MIT Press, Cambridge Mass.

[19] Layard PRG, Nickell SJ., 1986. Unemployment in Britain. Economica; 53; 121-170.

[20] Layard PRG, Nickell SJ, Jackman R., 1991. Unemployment: Macroeconomic Performance and the Labour Market. Oxford University Press, Oxford.

[21] Li H, Maddala GS., 1996. Bootstrapping Time Series models. Econometric Reviews; 15; 115-58.

[22] Matthews K, Minford P, Naraidoo R., 2008. Vicious and Virtuous Circles of Unemployment. Explaining UK and US Interwar Unemployment. European Journal of Political Economy; 3; 605-14.

[23] Meltzer AH, Richard SF., 1981. A Rational Theory of the Size of Government. Journal of Political Economy; 89; 914-28.

[24] Minford APL., 1983. Labour market equilibrium in an open economy. Oxford Economic Papers; 35; S207-S244.

[25] Mortensen D, Pissarides C., 1994. Job creation and job destruction in the Theory of Unemployment. Review of Economic Studies; 61; 397-416.

[26] Nickell S., 1997. Unemployment and Labour Market Rigidities: Europe versus North America. Journal of Economic Perspectives; 11; 54-74.

[27] Nickell S, Layard R., 1998. Labour Market Institutions and Economic Performance. Centre for Economic Performance; Discussion Paper 407.

[28] Nickell S, Nunziata L, Ochel W., 2005. Unemployment in the OECD Since the 1960s. What Do We Know?. Economic Journal; 115; 1-27.

[29] North DC., 1981. Structure and change in economic history. MIT Press, Cambridge Mass.

[30] Olson M., 1971. The logic of collective action: public goods and the theory of groups. Harvard University Press, Cambridge Mass.

[31] Olson M., 1982. The rise and decline of nations: economic growth, stagflation, and social rigidities. Yale University Press, Yale.

[32] Pencavel J., 1994. British unemployment: letter from America. Economic Journal; 104; 621-632.

[33] Perotti R., 1993. Political equilibrium, income distribution and growth. Review of Economic Studies; $60 ; 755-776$. 
[34] Persson T, Tabellini G., 1994. Is inequality harmful for growth. American Economic Review; 84; 600-621.

[35] Roed K., 1997. Hysteresis in unemployment. Journal of Economic Surveys; 11; 389-418.

[36] Saint-Paul G., 1996. Exploring the Political Economy of Labour Market Institutions. Economic Policy; $22 ; 263-315$.

[37] Saint-Paul G., 2000. The Political Economy of Labour Market Institutions. Oxford University Press, Oxford.

[38] Saint-Paul G., 2002. The Political Economy of Employment Protection. Journal of Political Economy; $110 ; 672-701$.

[39] Saint-Paul G., 2004. Why Are European Countries Diverging in Their Unemployment Experience? Journal of Economic Perspectives; 18; 49-68.

[40] Shapiro C, Stiglitz J., 1984. Equilibrium Unemployment as a Discipline Device. American Economic Review; 74; 433-444.

[41] Siebert H., 1997. Labour Market Rigidities: At the Root of Unemployment in Europe. Journal of Economic Perspectives; 11; 37-54.

[42] Skalin J, Teräsvirta T., 2002. Modeling asymmetries and moving equilibria in unemployment rates. Macroeconomic Dynamics; 2; 202-241.

[43] van der Horst A., 2003. Structural Estimates of Equilibrium Unemployment in Six OECD Economies. European Network of Economic Policy Research Institutes; Economic Working Papers 022.

[44] van Dijk D, Franses PH., 2003. Selecting a nonlinear time series model using weighted tests of equal forecast accuracy. Oxford Bulletin of Economics and Statistics; 65; 727-744.

[45] West KD., 2001. Tests for forecast encompassing when forecasts depend on estimated regression parameters. Journal of Business and Economic Statistics; 19; 29-33.

[46] West KD., 1996. Asymptotic inference about predictive ability. Econometrica; 64; 1067-1084.

[47] West KD, McCracken MW., 1998. Regression based tests of predictive ability. International Economic Review; 39; 817-840.

[48] Wright R., 1986. The redistributive roles of unemployment insurance and the dynamics of voting. Journal of Public Economics; 31; 377-399. 


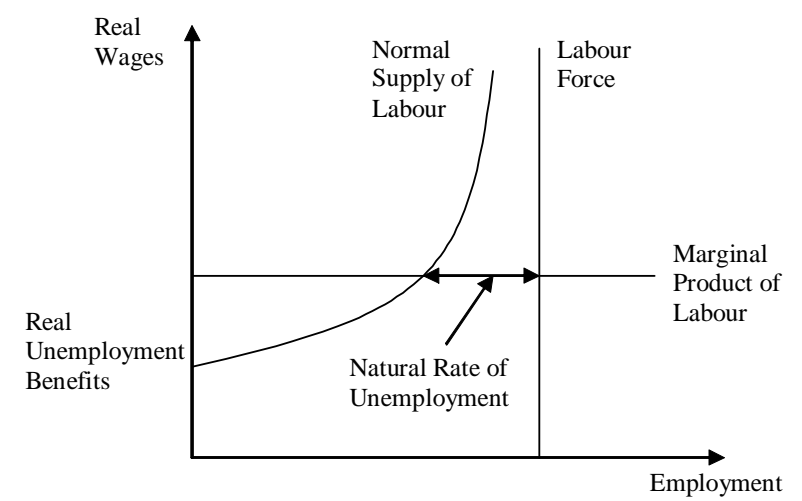

Figure 1: The Natural Rate of Unemployment

Table 1

Descriptive statistics of the observed unemployment rate

\begin{tabular}{llllllll}
\hline & Denmark & Finland & France & Germany & Ireland & Italy & Netherlands \\
\hline Min $U_{t}$ & 0.8 & 1 & 2.1 & 0.5 & 3.8 & 3.5 & 2 \\
Max $U_{t}$ & 12.5 & 17.9 & 12.5 & 11.7 & 18.1 & 12.2 & 9.9 \\
Mean & 6.98 & 6.07 & 7.91 & 5.58 & 9.59 & 8.23 & 5.81 \\
Median & 7.1 & 5.2 & 8.9 & 5.8 & 8.1 & 7.9 & 5.6 \\
Std. Deviation & 3.03 & 4.25 & 3.20 & 3.5 & 4.33 & 2.57 & 2.02 \\
Skewness & -0.33 & 0.92 & -0.49 & -0.01 & 0.36 & 0.08 & 0.06 \\
Kurtosis & 2.47 & 3.08 & 2 & 1.67 & 1.65 & 1.61 & 2.21 \\
\hline & Norway & Spain & Sweden & UK & US & & \\
\hline Min $U_{t}$ & 1.1 & 0.9 & 1.4 & 1.3 & 3.4 & & \\
Max $U_{t}$ & 6.1 & 24.6 & 8.6 & 11.2 & 10.7 & & \\
Mean & 3.33 & 11.53 & 4.05 & 4.94 & 5.85 & & \\
Median & 3.2 & 10.9 & 3.1 & 3.9 & 5.6 & & \\
Std. Deviation & 1.41 & 7.73 & 2.29 & 3.12 & 1.43 & & \\
Skewness & 0.29 & -0.01 & 0.57 & 0.73 & 0.75 & & \\
Kurtosis & 1.84 & 1.58 & 1.9 & 2.08 & 3.71 & & \\
\hline
\end{tabular}


Table 2

Reduced form Parameter Estimates

\begin{tabular}{|c|c|c|c|c|c|c|}
\hline & Denmark & Finland & France & Germany & Ireland & Italy \\
\hline \multirow[t]{2}{*}{$\hat{\mathrm{a}}_{0}$} & $-0.177^{* *}$ & $0.045^{* *}$ & $0.225^{* *}$ & $-0.526^{* *}$ & $0.610^{* *}$ & $0.518^{* *}$ \\
\hline & $(0.030)$ & $(0.017)$ & $(0.014)$ & $(0.021)$ & $(0.023)$ & $(0.044)$ \\
\hline \multirow[t]{2}{*}{$\hat{\mathrm{a}}_{1}$} & $0.434^{* *}$ & $0.353^{* *}$ & $0.328^{* *}$ & $0.567^{* *}$ & $0.230^{* *}$ & $0.260^{* *}$ \\
\hline & $(0.009)$ & $(0.005)$ & $(0.004)$ & $(0.009)$ & $(0.005)$ & $(0.011)$ \\
\hline \multirow[t]{2}{*}{$\hat{\mathrm{a}}_{2}$} & $-0.018^{* *}$ & $-0.012^{* *}$ & $-0.012^{* *}$ & $-0.028^{* *}$ & $-0.006^{* *}$ & $-0.008^{* *}$ \\
\hline & $(0.001)$ & $(0.001)$ & $(0.001)$ & $(0.001)$ & $(0.001)$ & $(0.001)$ \\
\hline \multirow[t]{2}{*}{$\xi_{t-1}$} & $0.852^{* *}$ & $0.579^{* *}$ & $0.768^{* *}$ & $0.772^{* *}$ & $0.347^{* *}$ & \\
\hline & $(0.080)$ & $(0.072)$ & $(0.052)$ & $(0.048)$ & $(0.073)$ & \\
\hline \multirow[t]{2}{*}{$\xi_{t-2}$} & -0.241 & $0.157^{*}$ & & & $0.180^{* *}$ & $0.219^{* *}$ \\
\hline & $(0.080)$ & $(0.082)$ & & & $(0.077)$ & $(0.071)$ \\
\hline \multirow[t]{2}{*}{$\xi_{t-3}$} & & $0.272^{* *}$ & & & $0.138^{*}$ & $0.219^{* *}$ \\
\hline & & $(0.082)$ & & & $(0.074)$ & $(0.071)$ \\
\hline \multirow[t]{2}{*}{$\xi_{t-4}$} & & $-0.188^{* *}$ & & & & $-0.193^{* *}$ \\
\hline & & $(0.071)$ & & & & $(0.072)$ \\
\hline $\mathrm{se}^{b}$ & 0.086 & 0.082 & 0.032 & 0.105 & 0.046 & 0.046 \\
\hline$\overline{\mathrm{R}}^{2}$ & 0.981 & 0.988 & 0.996 & 0.988 & 0.990 & 0.981 \\
\hline \multirow[t]{2}{*}{$\mathrm{F}$ ar } & $1.95[0.09]$ & $1.03[0.40]$ & $0.72[0.61]$ & $0.60[0.70]$ & $2.21[0.06]$ & $2.20[0.05]$ \\
\hline & Netherlands & Norway & Spain & Sweden & 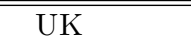 & $\overline{\mathrm{USS}}$ \\
\hline \multirow[t]{2}{*}{$\hat{\mathrm{a}}_{0}$} & 0.040 & $-0.257^{* *}$ & 0.009 & $-0.205^{* *}$ & $-0.075^{* *}$ & $0.317^{* *}$ \\
\hline & $(0.030)$ & $(0.068)$ & $(0.0146)$ & $(0.029)$ & $(0.014)$ & $(0.038)$ \\
\hline \multirow[t]{2}{*}{$\hat{\mathrm{a}}_{1}$} & $0.405^{* *}$ & $0.550^{* *}$ & $0.301^{* *}$ & $0.512^{* *}$ & $0.434^{* *}$ & $0.324^{* *}$ \\
\hline & $(0.011)$ & $(0.042)$ & $(0.003)$ & $(0.015)$ & $(0.006)$ & $(0.012)$ \\
\hline \multirow[t]{2}{*}{$\hat{\mathrm{a}}_{2}$} & $-0.019^{* *}$ & $-0.035^{* *}$ & $-0.007^{* *}$ & $-0.029^{* *}$ & $-0.020^{* *}$ & $-0.013^{* *}$ \\
\hline & $(0.001)$ & $(0.006)$ & $(0.001)$ & $(0.0020)$ & $(0.001)$ & $(0.001)$ \\
\hline \multirow[t]{2}{*}{$\xi_{t-1}$} & $0.412^{* *}$ & & $0.602^{* *}$ & $0.392^{* *}$ & $0.813^{* *}$ & $0.654^{* *}$ \\
\hline & $(0.081)$ & & $(0.073)$ & $(0.081)$ & $(0.042)$ & $(0.058)$ \\
\hline \multirow[t]{2}{*}{$\xi_{t-2}$} & & $0.282^{* *}$ & $0.328^{* *}$ & $0.238^{* *}$ & & \\
\hline & & $(0.083)$ & $(0.073)$ & $(0.081)$ & & \\
\hline \multirow[t]{2}{*}{$\xi_{t-3}$} & $0.301^{* *}$ & $0.187^{* *}$ & & & & \\
\hline & $(0.082)$ & $(0.084)$ & & & & \\
\hline$\xi_{t-4}$ & & $\begin{array}{l}-0.204^{* *} \\
(0.085)\end{array}$ & & & & \\
\hline se & 0.045 & 0.110 & 0.078 & 0.072 & 0.047 & 0.039 \\
\hline$\overline{\mathrm{R}}^{2}$ & 0.987 & 0.938 & 0.995 & 0.984 & 0.995 & 0.974 \\
\hline $\mathrm{F}$ ar & $0.86[0.51]$ & $0.47[0.80]$ & $2.85[0.02]$ & $1.18[0.32]$ & $0.90[0.48]$ & $1.28[0.28]$ \\
\hline
\end{tabular}

Notes: Two asterisks denotes statistical significance at the $5 \%$ level and one asterisk at the $10 \%$ level. Newey-West standard error estimates are provided below parameter estimates in parenthesis. se is standard error of regression and $\mathrm{F}$ ar is the Lagrange multiplier F-test for residual serial correlation of up to fifth order.

\section{Table 3}

The estimated equilibria

\begin{tabular}{lllllll}
\hline & Denmark & Finland & France & Germany & Ireland & Italy \\
\hline low $\bar{u}$ & 1.58 & 2.00 & 3.04 & 1.02 & 6.08 & 5.46 \\
middle $\bar{u}$ & 6.95 & 6.39 & 6.55 & 5.00 & 9.76 & 6.27 \\
high $\bar{u}$ & 10.75 & 15.1 & 11.4 & 10.11 & 14.92 & 11.4 \\
\hline & Netherlands & Norway & Spain & Sweden & UK & US \\
\hline low $\bar{u}$ & 1.99 & 2.01 & 1.57 & 2.10 & 2.08 & 5.01 \\
middle $\bar{u}$ & 5.74 & 3.95 & 11.27 & 4.10 & 5.33 & \\
high $\bar{u}$ & 8.29 & 5.45 & 20.82 & 7.69 & 10.02 & \\
\hline
\end{tabular}

Notes: Low and high equilibria are stable, the middle unstable 


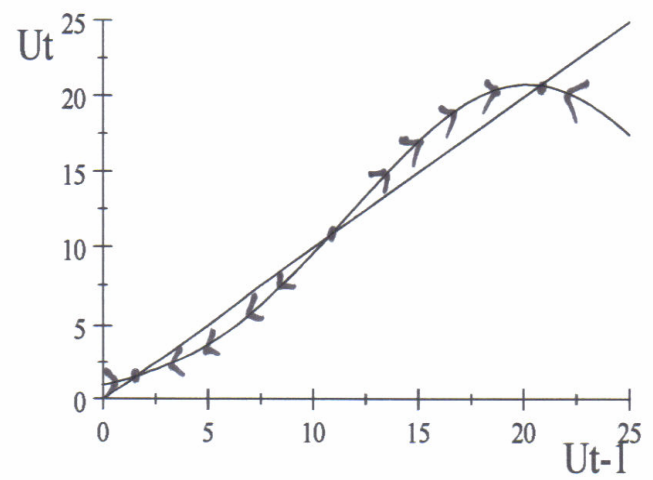

Figure 3. Spain phase diagram

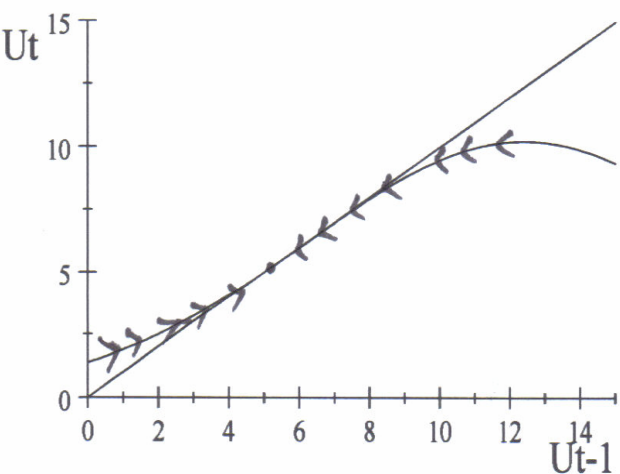

US phase diagram

Note: The diagrams depict $U_{t}=\exp \left(a_{0}+a_{1} U_{t-1}+a_{2} U_{t-1}^{2}\right)$ against $U_{t}=U_{t-1}$. In the first diagram we set $U_{t-1}$ $\in[0, \max 25]$, i.e., the $\mathrm{x}$-axis corresponds to the interval $[0, \max 25]$ and in the second diagram $U_{t-1} \in[0, \max 15]$.

Table 4

Bootstrap Estimates

\begin{tabular}{lllllll}
\hline Countries & $\hat{\mathrm{a}}_{0}$ & $95 \%$ C.I & $\hat{\mathrm{a}}_{1}$ & $95 \%$ C.I & $\hat{\mathrm{a}}_{2}$ & $95 \%$ C.I \\
\hline Denmark & -0.177 & $-0.236,-0.115$ & 0.434 & $0.415,0.453$ & -0.018 & $-0.019,-0.017$ \\
& 0.031 & & 0.010 & & 0.001 & \\
Finland & 0.045 & $0.013,0.077$ & 0.353 & $0.343,0.363$ & -0.012 & $-0.012,-0.011$ \\
& 0.016 & & 0.005 & & 0.001 & \\
France & 0.225 & $0.196,0.252$ & 0.328 & $0.320,0.337$ & -0.012 & $-0.012,-0.011$ \\
& 0.014 & & 0.004 & & 0.001 & \\
Germany & -0.527 & $-0.582,-0.494$ & 0.567 & $0.553,0.594$ & -0.028 & $-0.031,-0.027$ \\
& 0.0212 & & 0.0101 & & 0.001 & \\
Ireland & 0.610 & $0.563,0.654$ & 0.230 & $0.220,0.242$ & -0.006 & $-0.007,-0.005$ \\
& 0.023 & & 0.005 & & 0.001 & \\
Italy & 0.517 & $0.350,0.550$ & 0.260 & $0.251,0.304$ & -0.008 & $-0.011,-0.008$ \\
& 0.043 & & 0.011 & & 0.001 & \\
Netherlands & 0.040 & $-0.022,0.097$ & 0.405 & $0.384,0.427$ & -0.019 & $-0.021,-0.017$ \\
\multirow{4}{*}{ Norway } & 0.030 & & 0.011 & & 0.001 & \\
& -0.260 & $-0.401,-0.118$ & 0.551 & $0.465,0.634$ & -0.036 & $-0.047,-0.024$ \\
Sweden & 0.073 & & 0.044 & & 0.006 & \\
& -0.205 & $-0.262,-0.145$ & 0.512 & $0.481,0.543$ & -0.029 & $-0.032,-0.026$ \\
Spain & 0.029 & & 0.015 & & 0.002 & \\
& 0.009 & $-0.018,0.034$ & 0.301 & $0.295,0.307$ & -0.007 & $-0.008,-0.007$ \\
UK & 0.014 & & 0.003 & & 0.001 & \\
& -0.075 & $-0.100,-0.047$ & 0.434 & $0.422,0.444$ & -0.020 & $-0.020,-0.019$ \\
US & 0.014 & & 0.006 & & 0.001 & \\
& 0.319 & $0.246,0.395$ & 0.323 & $0.299,0.346$ & -0.013 & $-0.015,-0.011$ \\
& 0.038 & & 0.012 & & 0.001 & \\
\hline
\end{tabular}

Notes: Below each parameter estimate, we report its standard error and confidence intervals,

based on 1000 re-estimations. 


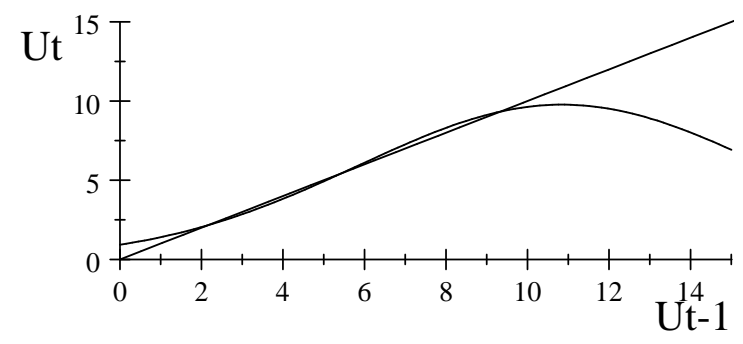

UK

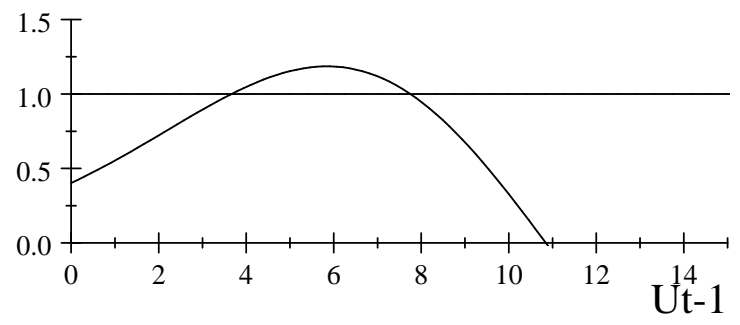

UK's Slope

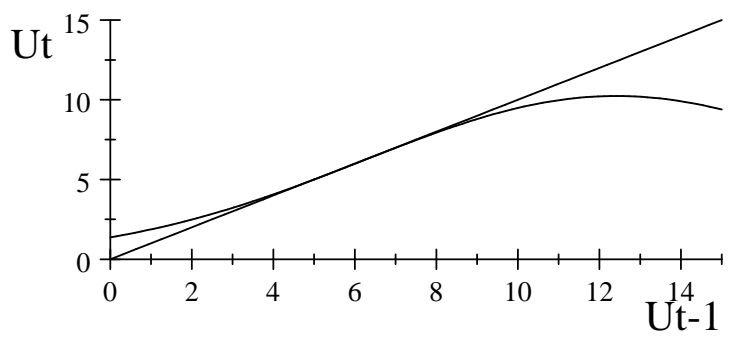

US

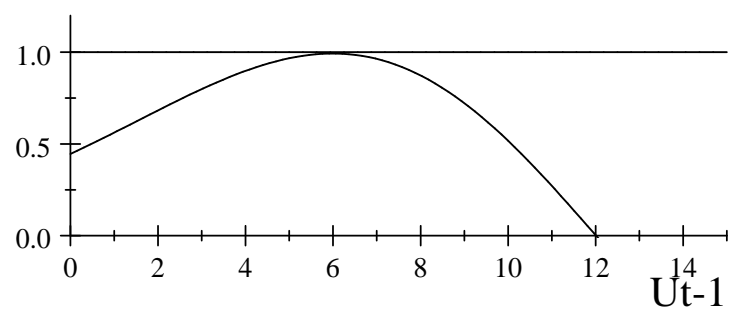

US Slope

Figure 4. Features of 1-equilibrium and 3-equilibrium models

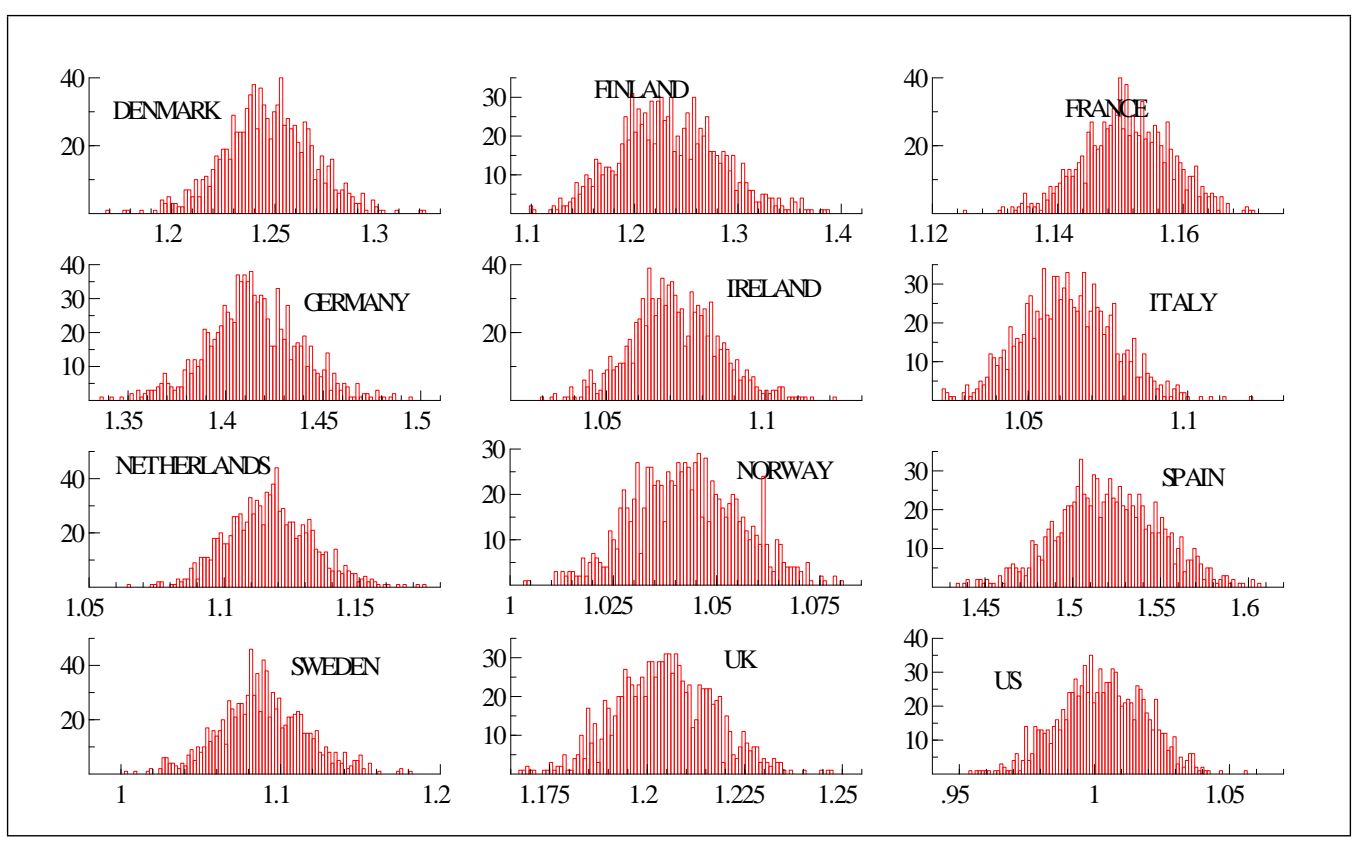

Figure 5. Countries Distribution over $\sigma$ 
Table 5

Summary Statistics for the Slope Estimate $\sigma$

\begin{tabular}{cllllll}
\hline Countries & Denmark & Finland & France & Germany & Ireland & Italy \\
\hline $\begin{array}{c}\text { Mean } \\
\text { Std }\end{array}$ & 1.247 & 1.233 & 1.151 & 1.414 & 1.072 & 1.063 \\
$\begin{array}{l}\text { Deviation } \\
95 \% \text { C.I }\end{array}$ & 0.021 & 0.0496 & 0.007 & 0.024 & 0.017 & 0.015 \\
$99 \%$ C.I & $1.204,1.288$ & $1.145,1.335$ & $1.137,1.165$ & $1.366,1.462$ & $1.045,1.100$ & $1.035,1.091$ \\
Estimated $\widehat{\sigma}$ & 1.253 & $1.120,1.365$ & $1.325,1.168$ & $1.352,1.480$ & $1.036,1.110$ & $1.025,1.099$ \\
Countries & Netherlands & Norway & Spain & Sweden & UK & US \\
\hline $\begin{array}{l}\text { Mean } \\
\text { Std }\end{array}$ & 1.117 & 1.043 & 1.520 & 1.089 & 1.204 & 1.002 \\
Deviation & 0.016 & 0.013 & 0.029 & 0.027 & 0.012 & 0.016 \\
$95 \%$ C.I & $1.088,1.148$ & $1.017,1.068$ & $1.464,1.578$ & $1.033,1.147$ & $1.181,1.229$ & $0.970,1.034$ \\
$99 \%$ C.I & $1.076,1.160$ & $1.012,1.074$ & $1.446,1.592$ & $1.020,1.158$ & $1.170,1.236$ & $0.960,1.040$ \\
Estimated $\hat{\sigma}$ & 1.119 & 1.043 & 1.518 & 1.085 & 1.197 & 1.001
\end{tabular}

Table 6

ARMA Model Statistics and In-sample fit comparison

\begin{tabular}{|c|c|c|c|c|c|c|c|c|c|c|c|}
\hline & $\hat{\alpha}$ & $\hat{\beta}$ & $\hat{\theta}_{1}$ & $\hat{\theta}_{2}$ & $\hat{\theta}_{3}$ & $\bar{R}^{2}(\mathrm{R})$ & se & $\mathrm{F}$ ar & $\bar{R}^{2}(\mathrm{M})$ & $95 \%$ C.I of $\sigma_{M} / \sigma_{R}$ & $\hat{\sigma}_{M} / \hat{\sigma}_{R}$ \\
\hline Denmark & $\begin{array}{l}2.102^{* *} \\
(0.189)\end{array}$ & $\begin{array}{l}0.954^{* *} \\
(0.038)\end{array}$ & $\begin{array}{l}0.546^{* *} \\
(0.110)\end{array}$ & & & 0.980 & 0.088 & $\begin{array}{l}0.687 \\
(0.505)\end{array}$ & 0.980 & $0.860,1.120$ & 0.976 \\
\hline Finland & $\begin{array}{l}1.823^{* *} \\
(0.462)\end{array}$ & $\begin{array}{l}0.972^{* *} \\
(0.017)\end{array}$ & $\begin{array}{l}0.342^{* *} \\
(0.123)\end{array}$ & $\begin{array}{l}0.279^{* *} \\
(0.058)\end{array}$ & $\begin{array}{c}0.498^{* *} \\
(0.086)\end{array}$ & 0.989 & 0.085 & $\begin{array}{l}0.874 \\
(0.419)\end{array}$ & 0.986 & $0.867,1.165$ & 1.032 \\
\hline France & $\begin{array}{l}2.677^{* *} \\
(0.503)\end{array}$ & $\begin{array}{l}0.987^{* *} \\
(0.011)\end{array}$ & $\begin{array}{l}0.493^{* *} \\
(0.100)\end{array}$ & & & 0.997 & 0.031 & $\begin{array}{l}1.600 \\
(0.206)\end{array}$ & 0.996 & $0.850,1.120$ & 1.028 \\
\hline Germany & $\begin{array}{l}2.058^{* *} \\
(0.522)\end{array}$ & $\begin{array}{l}0.979^{* *} \\
(0.017)\end{array}$ & $\begin{array}{l}0.455^{* *} \\
(0.136)\end{array}$ & $\begin{array}{l}0.187^{* *} \\
(0.099)\end{array}$ & & 0.989 & 0.093 & $\begin{array}{l}2.320 \\
(0.102)\end{array}$ & 0.986 & $0.842,1.350$ & 1.125 \\
\hline Ireland & $\begin{array}{l}2.066^{* *} \\
(0.594)\end{array}$ & $\begin{array}{l}0.985^{* *} \\
(0.017)\end{array}$ & $\begin{array}{l}0.311^{* *} \\
(0.134)\end{array}$ & $\begin{array}{l}0.290^{* *} \\
(0.089)\end{array}$ & $\begin{array}{c}0.233^{* *} \\
(0.099)\end{array}$ & 0.984 & 0.047 & $\begin{array}{l}0.480 \\
(0.620)\end{array}$ & 0.985 & $0.873,1.055$ & 0.970 \\
\hline Italy & $\begin{array}{l}2.428^{* *} \\
(0.425)\end{array}$ & $\begin{array}{l}0.990^{* *} \\
(0.013)\end{array}$ & & & & 0.979 & 0.048 & $\begin{array}{l}1.993 \\
(0.140)\end{array}$ & 0.981 & $0.889,1.048$ & 0.949 \\
\hline Netherlands & $\begin{array}{l}2.117^{* *} \\
(0.353)\end{array}$ & $\begin{array}{l}1.029^{* *} \\
(0.019)\end{array}$ & & $\begin{array}{l}0.219^{* *} \\
(0.112)\end{array}$ & $\begin{array}{l}0.285^{* *} \\
(0.153)\end{array}$ & 0.982 & 0.050 & $\begin{array}{l}2.058 \\
(0.133)\end{array}$ & 0.986 & $0.804,1.117$ & 0.896 \\
\hline Norway & $\begin{array}{l}1.192^{* *} \\
(0.236)\end{array}$ & $\begin{array}{l}0.950^{* *} \\
(0.023)\end{array}$ & $\begin{array}{l}-0.215 \\
(0.132)\end{array}$ & $\begin{array}{l}0.380^{* *} \\
(0.075)\end{array}$ & & 0.931 & 0.113 & $\begin{array}{l}2.067 \\
(0.131)\end{array}$ & 0.933 & $0.867,1.059$ & 0.975 \\
\hline Sweden & $\begin{array}{l}1.328^{* *} \\
(0.348)\end{array}$ & $\begin{array}{l}0.965^{* *} \\
(0.023)\end{array}$ & $\begin{array}{c}0.342^{* *} \\
(0.083)\end{array}$ & $\begin{array}{l}0.302^{* *} \\
(0.069)\end{array}$ & $\begin{array}{l}0.223^{* *} \\
(0.076)\end{array}$ & 0.981 & 0.075 & $\begin{array}{l}1.793 \\
(0.171)\end{array}$ & 0.983 & $0.862,0.982$ & 0.958 \\
\hline UK & $\begin{array}{l}1.678^{* *} \\
(0.430)\end{array}$ & $\begin{array}{l}0.978^{* *} \\
(0.015)\end{array}$ & $\begin{array}{l}0.672^{* *} \\
(0.115)\end{array}$ & $\begin{array}{l}0.456^{* *} \\
(0.108)\end{array}$ & $\begin{array}{l}0.262^{* *} \\
(0.111)\end{array}$ & 0.994 & 0.048 & $\begin{array}{l}1.080 \\
(0.342)\end{array}$ & 0.994 & $0.843,1.154$ & 0.981 \\
\hline US & $\begin{array}{l}1.734^{* *} \\
(0.115)\end{array}$ & $\begin{array}{l}0.927^{* *} \\
(0.034)\end{array}$ & $\begin{array}{l}0.685^{* *} \\
(0.081)\end{array}$ & $\begin{array}{l}0.568^{* *} \\
(0.073)\end{array}$ & $\begin{array}{l}0.512^{* *} \\
(0.064)\end{array}$ & 0.977 & 0.038 & $\begin{array}{l}1.467 \\
(0.234)\end{array}$ & 0.976 & $0.800,1.015$ & 1.029 \\
\hline
\end{tabular}

Notes: Two asterisks denotes statistical significance at the $5 \%$ level and one asterisk at the $10 \%$ level. Newey-West standard error estimates are provided below parameter estimates in parenthesis. se is standard error of regression and $\mathrm{F}$ ar is the Lagrange multiplier F-test for residual serial correlation of up to fifth order. 
Table 7

Forecast Comparison

\begin{tabular}{|c|c|c|c|c|c|c|c|}
\hline & \multicolumn{7}{|c|}{ Countries } \\
\hline & France & Germany & Ireland & Italy & U.K & U.S & Spain \\
\hline MSF & 0.0004 & 0.0027 & 0.0015 & 0.0008 & 0.0005 & 0.0011 & 0.0047 \\
\hline $\operatorname{MSPE}(\mathrm{R})$ & 0.0086 & 0.0149 & 0.0251 & 0.0083 & 0.0103 & 0.0013 & 0.0314 \\
\hline DM & 3.83 & 3.94 & 5.24 & 4.83 & 6.04 & 1.80 & 4.60 \\
\hline
\end{tabular}

Notes: One step ahead forecast comparison. The $D M$ tests is $N(0,1)$ distributed. The null hypothesis is equal forecasting accuracy for the M and Rmodel forecasts.

Table 8

Forecast Comparison

\begin{tabular}{|c|c|c|c|c|c|}
\hline & \multicolumn{5}{|l|}{ Countries } \\
\hline & Denmark & Finland & Sweden & Norway & Netherlands \\
\hline MSPE(M) & 0.0013 & 0.0004 & 0.0035 & 0.0028 & 0.0031 \\
\hline $\operatorname{MSPE}(\mathrm{R})$ & 0.0021 & 0.0021 & 0.0243 & 0.0035 & 0.0508 \\
\hline DM & 1.587 & 3.77 & 5.60 & 1.45 & 4.98 \\
\hline
\end{tabular}

Notes: One step ahead forecast comparison. The $D M$ tests is $N(0,1)$ distributed. The null hypothesis is equal forecasting accuracy for the $\mathrm{M}$ and Rmodel forecasts. 


\section{Appendix 1}

This Appendix discusses the derivation of equation (7) in the text. Equation (4) in the text can be rewritten, once expectations are taken, as:

$$
V_{t}^{m}=\sum_{i=0}^{\infty} \beta^{i}\left(\pi_{t+i} E_{t} B_{t+i}+\left[1-\pi_{t+i}\right] E_{t} W_{t+i}+r K-T\right)
$$

Now we will treat $W$ (wages, i.e. productivity) as a random walk. We expect productivity to be nonstationary (an I(1) process) because productivity growth is by its nature an innovation. If in addition to this random shock, productivity growth was related to past shocks making it an ARIMA process integrated of order 1 then future wages would be related to current wages by a linear function of the autocorrelation and moving average parameters; however for simplicity here we assume it is a simple random walk so that $E_{t} W_{t+i}=W_{t}$. We also assume that the voters can only demand at any point of time a single, constant, benefit level (because political debate enforces simplicity), and thus they must decide on a single $B_{t}$ at each date $\mathrm{t}$; this will not prevent them at a later date demanding a different one but at $\mathrm{t}$ they cannot demand a level that is planned to change. From these arguments we may further rewrite (A1) as:

$$
V_{t}^{m}=\frac{1}{1-\beta}\left(W_{t}+r K-T\right)+\left(\pi_{0}+\pi \bar{U}_{t}\right)\left(B_{t}-W_{t}\right)
$$

where the permanent value of unemployment $\bar{U}_{t}$ is given by:

$$
\bar{U}_{t}=\exp \left(u_{0}\right) \cdot\left(E_{t} \sum_{i=0}^{\infty} \beta^{i} \exp v_{t+i}\right)\left[B_{t} / W_{t}\right]^{\delta}
$$

The first order condition for benefits from maximising (A2) is then:

$$
B_{t}=W_{t} \frac{\pi \delta \bar{U}_{t}}{\pi_{0}+(1+\delta) \pi \bar{U}_{t}}
$$

Inspection of (A4) reveals that median voters will demand a higher benefit-wage ratio as $\bar{U}_{t}$ rises but at a diminishing rate. Taking log first differences of (A4) yields:

$$
d \ln B_{t}=d \ln W_{t}+d \ln \left(\frac{\pi \delta \bar{U}_{t}}{\pi_{0}+(1+\delta) \pi \bar{U}_{t}}\right)=d \ln W_{t}+d \ln \bar{U}_{t}-d \ln \left(\pi_{0}+(1+\delta) \pi \bar{U}_{t}\right)
$$

Using the approximation that

$$
d \ln (x+z) \simeq \frac{x_{0}}{x_{0}+z_{0}} d \ln x+\frac{z_{0}}{x_{0}+z_{0}} d \ln z
$$

the last term in (A5) can be rewritten as $\left(\frac{(1+\delta) \pi \bar{U}_{0}}{\pi_{0}+(1+\delta) \pi \bar{U}_{0}}\right) d \ln \bar{U}_{t}$. Integrating throughout (A5) yields (A6) where constant is the constant of integration: 


$$
\ln B_{t}=\eta\left(\bar{U}_{0}\right) \ln \bar{U}_{t}+\ln W_{t}+\text { constant }
$$

Note that $\eta\left(\bar{U}_{0}\right) \ln \bar{U}_{t}$ has the required property that it rises with unemployment at a diminishing rate, where $\eta\left(\bar{U}_{0}\right)=\left(\frac{\pi_{0}}{\pi_{0}+(1+\delta) \pi \bar{U}_{0}}\right)$. By making $\bar{U}_{0}$ as close as possible to $\bar{U}_{t}$ the degree of approximation is minimised; thus we set $\bar{U}_{0}=\bar{U}_{t-1}$, so that now we have $\eta\left(\bar{U}_{t-1}\right)=\left(\frac{\pi_{0}}{\pi_{0}+(1+\delta) \pi \bar{U}_{t-1}}\right)$. We later use this piece of result when solving the model under limited information.

We also have from (A3):

$$
\ln \bar{U}_{t}=u_{0}+\delta\left(\ln B_{t}-\ln W_{t}\right)+\bar{v}_{t}^{e}
$$

where $\bar{v}_{t}^{e}=\left(E_{t} \sum_{i=0}^{\infty} \beta^{i} \exp v_{t+i}\right)$. We can then compactly write the solution for the median voter's desired benefits in loglinear terms as:

$$
\left(\ln B_{t}-\ln W_{t}\right)=\frac{\eta}{1-\delta \eta} \bar{v}_{t}^{e}+\text { constant }
$$

which is equation (7) in the text.

The median voter's problem is illustrated in Figure 2. The stability condition for the model is that the slope of the UU curve be greater than that of the BB curve; this also implies that a rise in expected $v$ causes a rise in benefits demanded.

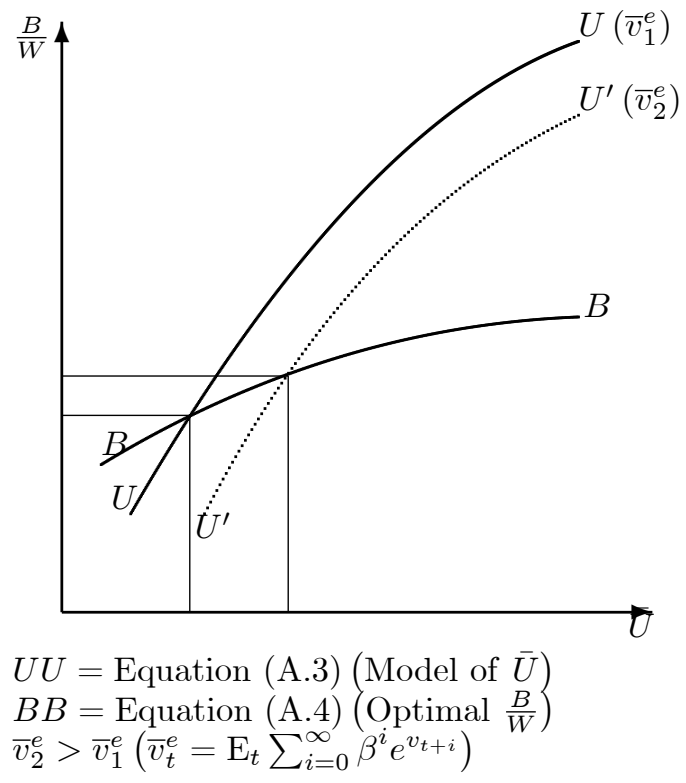

Figure 2: Voter choice of $\frac{B}{W}$ 